Marquette University

e-Publications@Marquette

College of Nursing Faculty Research and

Publications

Nursing, College of

6-1-1986

\title{
Toward a Definition of Nurse-Managed Centers
}

Richard Fehring

Marquette University, richard.fehring@marquette.edu

Judeen Schulte

Alverno College

Susan K. Riesch

University of Wisconsin - Milwaukee

Accepted version. Journal of Community Health Nursing, Vol. 3, No. 2 (June 1986): 59-67. DOI. (C) 1986 Taylor \& Francis. Used with permission. 


\section{Toward a Definition of Nurse-Managed Centers}

By Richard J. Fehring, Judeen Schulte, and Susan K. Riesch

The purpose of this study was to gain consensus on a definition of Nurse-Managed Centers. To accomplish this task, Delphi survey methods were used with the participants of the Second Biennial Conference on Nurse-Managed Centers. Delphi methods entail obtaining autonomous consensus from experts through rounds of questionnaires and feedback of results. A questionnaire was developed that included 22 items obtained from the literature, past conferences, and the expertise of the authors. An additional 6 items were suggested by the conferees. Of the 168 conferees, 148 participated in the first round, 147 in the second, and 133 in the third. Fifty-three percent of the respondents were educators, 22\% administrators, and $11 \%$ clinicians. More than $75 \%$ of the respondents were masters prepared. After the third round, the highest-ranked items indicated that NMCs should provide direct access for clients to professional nursing, be part of a strong referral network, base services on client participation, and provide holistic treatment. A definition was formulated and associations between ranked items and selected demographic characteristics were analyzed.

Although Nurse-Managed Centers (NMCs) are being planned, developed, and implemented across the country, there is some confusion about the definition of NMCs. In 1982, the First Biennial Conference on Nurse-Managed Centers was held in Milwaukee. At that conference, NMCs were defined as settings "in which care was nurse managed and which had potential for student learning, faculty practice, and nursing research" (Riesch, 1982). This definition, however, could be applied to almost any setting in which nurses practice professional nursing, and such a view was validated by the many diverse models of NMCs represented at that conference. In order to gather consensus on a definition of NMCs, a Delphi survey was conducted with the participants of the 1984 Second Bienniel Conference on Nurse-Managed Centers serving as experts.

\section{Background}

A number of published articles have described the development of NMCs where professional nursing is delivered independent of existing health institutions (Arlton \& Miercort, 1980; Clark, 1984; Grimes \& Stamps, 1980; Hauf, 1977; Mezey \& Chiamulera, 1980; Ossler, Goodwin, Mariani, \& Gilliss, 1982; Riesch, Felder, \& Stauder, 1980). These NMCs were

Fehring, Schulte, Riesch 1 
developed to provide accessible settings for faculty and students to practice professional nursing and wellness-oriented health care that customarily is not administered in the traditional health care setting. With the rapid changes in the health care system providing at least one impetus, schools of nursing are developing NMCs and professional nurses are establishing their own businesses. Evidence for this trend has been gathered in an unpublished national survey that described 63 operating NMCs in 1981 and over 100 in the planning stages (Riesch, 1982).

Most of the NMCs reported in the literature focus on health promotion and disease prevention, provide direct access to professional nurses by consumers, are practice sites for faculty, and are learning sites for students typically enrolled in community health nursing courses. Services offered most frequently in the NMCs are health screening and assessment, health counseling and education, group sessions on health topics, support groups, and health fairs. The clients served in these NMCs are varied but are often underserved populations in the traditional health care setting (e.g., well students and well elderly). The sites for these NMCs include churches, low-income family housing projects, housing projects for the elderly, and campus settings. Fees for service are minimal or nonexistent and usually do not support the salaries of the faculty. This has potential for change with legislation to be proposed for reimbursement for nursing care (American Nurses' Association, 1985; Wyden, 1984). Many of the centers reported in the literature are grant supported. Both graduate and undergraduate students use the NMCs as practice sites to meet objectives of nursing programs (Clark, 1984; Damen, 1980; Hauf, 1977; Herman \& Krall, 1984).

In an address to the American Public Health Association, Henry (1978) proposed the development of nursing centers as demonstration models for nursing practice, education, and research. Henry envisioned nursing centers as

centers which could be placed in a variety of settings, that is, institutional, primary care, or community settings, where the education of nursing students, the practice of patient care, and the research to improve both (education and practice) are planned and carried out. Nursing would be the primary focus of the centers. Nurses would have the responsibility for the administration of the setting and its funds, and for coordinating all care provided to patients including that provided by other health disciplines. The operation of such settings would have a multiple effect in their contribution to improved education and practice for all nurses, and most importantly, would result in a significant improvement in the nursing care rendered to patients. (p. 2)

Fehring, Schulte, Riesch 2 
Lang (1983) defined NMCs as "places where client/patients receive care that is completely managed by nurses, and where education and research components are built in" ( $p$. 1291). Lang, however, questioned whether NMCs need to be managed by nurses, because the issue was control of nursing practice. She also questioned the type of services delivered in NMCs and the level of preparation of nurses practicing in such centers. Lang suggested that the American Nurses' Association's Nursing: A Social Policy Statement (1980) be the guide for answering these questions.

As evidenced by these statements, there are many questions surrounding the definition of NMCs. The stimulus for this investigation was the First Biennial Conference on NurseManaged Centers in 1982 at which 100 nurses articulated many different models for NMCs. The purpose of this investigation was to attempt a beginning consensus from the experts who attended the 1984 Second Biennial Conference on Nurse- Managed Centers. The intent was not to limit the development and testing of diverse models of delivering nursing care but rather to provide a beginning framework for defining NMCs.

\section{Method}

In order to develop a consensus definition of NMCs, the Delphi method was used. The Delphi method was developed in the early 1950s for the Rand Corporation to obtain consensus on future defense needs (Helmer, 1983). The method is characterized by repeated rounds of questions, feedback, expert opinion, and autonomy. The method has been used for nursing concerns, especially for determining research priorities (Bond \& Bond, 1982; Lewandowski \& Kositsky, 1983; Lindeman, 1975; Snyder Hill, 1984).

\section{Sample}

The panel of experts for this study, or subjects, were the participants of the Second Biennial Conference on Nurse-Managed Centers conducted in 1984. Of the 168 registrants at the conference, 148 participated in the study. Of this group, 53\% were educators, $21 \%$ were administrators, and $11 \%$ were clinicians. More than $75 \%$ of the participants were masters prepared and had over 6 years of clinical experience. Forty eight percent of the experts had practiced in an NMC, and $44 \%$ had directed an NMC.

\section{Instrument}

The questionnaire for this study was developed by the authors. It included 22 items that were taken from the literature and past experience of the authors. The items were constructed 
around issues relevant to NMCs, that is, the philosophical bases for the development of NMCs, staffing patterns, patient care activities, and methods of delivery of care. The response format was a 7-point Likert-type scale ranging from not characteristic (I) to very characteristic (7) of an NMC. Each item contained the stem word "should" (e.g., "Nurse-managed centers should have a strong referral network"). The instrument was reviewed by nursing research colleagues for clarity, by a statistician for analysis purposes, and by selected staff from three NMCs for content. Although the items for the questionnaire were fixed, an opportunity was given for the participants to include pertinent items during the first round. Six items were suggested by participants and included in the second and third rounds of the survey. The coefficient alpha for all 28 items after the third round reached 0.713, indicating an acceptable level of internal consistency for the instrument. The questionnaire also included demographic items and a rating scale for self-perceived expertise with NMCs.

\section{Procedure}

Data collection occurred during the two days of the Second Biennial Conference on Nurse-Managed Centers. Directions for study participation and for the first round of questions were given during the morning of the first day of the conference. The participants were instructed to rate each item in terms of relevance to NMCs and to provide demographic data. The participants also were encouraged to add items to the questionnaire. The questionnaires were collected and computer analyzed.

The second round of questionnaires was distributed at the final session of the first day of the conference. The second-round questionnaire included the 22 original items, 6 new items generated by the participants from the first round, and the results of the first round. The results included the median, interquartile range, and range for each item. The respondents were asked to rate each item, in light of the results of the first round. If the participants responded to an item outside of the item's interquartile range, they were asked to provide written rationale. The intent of such rationale was to persuade others toward one's viewpoint. Results were tabulated and comments compiled for use with the third round of the survey.

The third and final round of the Delphi survey was conducted during the morning of the second day of the conference. Participants were supplied with responses from the second round, that is, the median, interquartile range, and range for each item and a summary of the written rationale by persons who responded outside the interquartile range. The participants again were asked to rate each item for its relevance to NMCs. The results from the final round were tabulated and presented to the participants at the end of the conference. 


\section{Results}

The rank, means, and standard deviations of each item from the third round of the Delphi survey are shown in Table 1. Results from the third round are displayed because they represent final confirmation and high feedback consensus. Twenty-two items received high consensus from the respondents ( $M>5.0$ ), indicating they were characteristic of NMCs. Two of the items had mean scores less than 3.0, indicating they were not characteristic of NMCs. These items referred to the biomedical disease model and non-nurse administration of the NMC. Four of the items had means less than 5.0 but greater than 3.0 , indicating indecisiveness among participants. These items referred to level of preparation for practice in NMC and the biomedical disease focus.

The means and rank of each item were analyzed for differences according to professional position (administrator, educator, or clinician) and according to self-perceived expertise in NMCs. No significant differences were found in the three groups in terms of agreement with the items.

\section{Definition}

From the high consensus items of the survey, a beginning definition of NMCs was formulated. This definition may guide the profession in the development of NMCs. The authors encourage discussion, further study, and refinement of this beginning definition:

Nurse-Managed Centers are organizations that provide direct access to professional nurses who offer holistic, client-centered health services for reimbursement. With the use of nursing models of health, professional nurses in NMCs diagnose and treat human responses to potential and actual health problems. Examples of professional nursing services include health education, health promotion, and health-related research. Services are targeted to underserved individuals and groups. An effective referral system and collaboration with other health care professionals are an integral part of NMCs. As models of professional nursing practice and research, NMCs are ideal sites for faculty and student practice. They are administered by a professional nurse.

\section{Analysis of Written Feedback}

The expert's written feedback to the instrument items during the second round contained several themes. First, several experts pleaded that the profession not move too quickly toward a 
definition of NMCs without adequate data. They cautioned against limiting the philosophy and activities of such centers.

Further, several experts observed that nursing must focus on the needs of its constituents, not its own needs. For instance, on the issue of reimbursement, nursing must demonstrate unique, nonduplicative services for which people will pay. Nursing cannot demand reimbursement for activities other professions can provide. In other words, nursing needs to go beyond a self-serving ideal and continue to be client-centered.

Another recurring theme involved inclusion of the biomedical model and nursing diagnosis. Several experts argued that holism includes the biomedical model and that people respond to that model of health care delivery. Before the biomedical model is excluded, these respondents urged that definitions and demonstrations of nursing models be accepted.

Through the comments, it was apparent that the experts were arguing for a well-defined, fair alternative to the present system of health care delivery. Comments such as "We should, given the present system of health care, receive third party reimbursement. But we need to work on alternative payment systems that will allow all people to receive health care regardless of ability to pay," showed that these experts were rejecting models which were not sensitive to the needs of the persons they served.

\section{Discussion}

According to the results of this study, there is considerable agreement among the respondents as to what characterizes an NMC. Clearly, NMCs involve direct access to professional nurses, holistic promotive health services, disease prevention, nursing diagnosis, nursing models, self-responsibility for health, consumer input, client participation, referral resources, patient education, service to underserved populations, faculty and student practice, and nursing research. There is considerable agreement that NMCs should not be administered by someone other than a professional nurse. The results also reveal considerable agreement among educators, clinicians, and administrators (who attended the Second Biennial Conference on Nurse-Managed Centers) as to which items are characteristic or not characteristic of NMCs. Similarly, there was high agreement among participants regardless of their degree of selfperceived expertise with NMCs.

Most of the high agreement items coincide with the descriptions of NMCs in the literature. However, Lang (1983) questioned whether an NMC needs to be managed by a professional nurse. She stated that what is important is that the nurse had control over managing nursing practice. Though the authors of this study agree with Lang, the participants in this study, 
whether they be educators, clinicians, or administrators, felt that NMCs should be administered by a professional nurse.

There is little agreement, however, among the respondents in three areas: (a) the educational preparation for practice in NMCs, (b) the use of the medical model, and (c) the relationship of the nurse in NMCs in diagnosing and treating medical problems. These areas are controversial within the profession and apparently are magnified within NMCs.

For example, on the topic of educational preparation for practice, if NMCs involve independent professional practice, for which the nurse is accountable for all activity Downloaded By: [Marquette University] At: 19:53 5 February 201066 Fehring, Schulte, Riesch from assessment through evaluation, then perhaps the master's degree should be entry-level preparation in NMCs. The master's-prepared nurse, the clinical nurse specialist, and some nurse practitioners are prepared for such an autonomous role (Ozimek \& Yura, 1975). On the other hand, if it can be demonstrated that the bachelor's-prepared nurse is capable of this practice, the BSN could be the entry level in NMCs. Analogies that may assist in clarification of this issue include practice paradigms within nursing and other disciplines. For example, community health nurses, usually with bachelor's preparation, manage caseloads of families, schools, and/or clinics autonomously, and the bachelor's-prepared teacher, social worker, occupational therapist, and physical therapist practice autonomously. The level of entry to practice in NMCs ultimately will be determined by the complexity of the care provided in such centers.

Whether NMCs can have both a nursing and medical focus is also an item of controversy. Although there was high consensus that NMCs should be based on nursing models, some of the respondents felt that this could and should include the biomedical disease model. Several respondents were adamant that the medical model should be excluded. Presumably, NMCs based on nursing models of health would allow nurses to have greater control and accountability for their client needs and care. Yet considerable work may be needed to develop definitions and demonstrations of nursing models.

Closely related to the controversy over the medical/nursing focus of NMCs is whether nurses should diagnose and treat medical problems in NMCs. Diagnosing and treating medical problems is a role attributed to the physician and, in some instances, extended to the nurse practitioner. Some of the existing NMCs use nurse practitioners extensively and employ medical doctors. Many NMCs deal with medical problems and either treat them under medical protocol, refer to medical authority, or view the problem from a "nursing standpoint." If the problem is 
treated from a nursing perspective, the client may be usually already under medical supervision and nursing care is complementary to the medical care (Sullivan, 1982).

The issues of educational preparation, use of medical models, and nurses' roles in diagnosis and treatment in NMCs are intraprofessional and were not resolved by this survey. Such issues, however, significantly affect the functioning of NMCs and thus need study and resolution. Though several questions were raised as a result of the survey, the primary objective of developing a beginning definition of NMCs was accomplished. We encourage continued discussion and research on the issues surrounding nurse-managed centers.

\section{Acknowledgement}

The authors thank the following for their assistance in the research and definition: Tom Callan, Phyllis Lensky, Carol Manternach, Charlene Ossler, Kim Pietsch, Lonna Taylor, Susan Westlake, Nancy Wright.

\section{References}

American Nurses' Association. (1980). Nursing: A social policy statement (Publication NP-63). Kansas City, MO: Author.

Arlton, D. M., \& Miercort, O. S. (1980). A nursing clinic: The challenge for student learning opportunities. Journal of Nursing Education, 19(1), 53-58.

Bond, S., \& Bond, J. (1982). A Delphi survey of clinical nursing research priorities. Journal of Advanced Nursing, 7, 565-575.

Clark, M. J. (1984, April). Nursing leadership in a shoestring clinic. Topics in Clinical Nursing, 6(1), 52-62.

Damen, J. (1980). Implementation of a campus nursing and health information center in the baccalaureate curriculum: Part 111 independent study project. Journal of Nursing Education, 19(5), 15-19.

Grimes, D., \& Stamps, C. (1980). Meeting the health care needs of older adults through a community nursing center. Nursing Administration Quarterly, 4, 31-40.

Hauf, B. J. (1977). An evaluation study of a nursing center for community health nursing student experience. Journal of Nursing Education, 16, 7-1 1.

Helmer, O. (1983). Looking forward: A guide to future research. Beverly Hills, CA: Sage.

Henry, O. M. (1978, October). Demonstration centers for nursing practice, education, and research. Paper presented at the annual meeting of the American Public Health Association, Los Angeles.

Fehring, Schulte, Riesch 8 
Herman, C. M., \& Krall, K. (1984). University sponsored home care agency as a clinical site. Image, 16(3), 71-80.

Lang, N. (1983). Nurse-managed centers, will they survive? American Journal of Nursing, 83, 1290- 1293.

Lewandowski, L,. S., \& Kositsky, A. M. (1983). Research priorities for critical care nursing: A study by the American Association of Critical Care Nurses. Heart and Lung, 12(1), 35-44.

Lindeman, C. A. (1975). Delphi survey of priorities in clinical nursing research. Nursing Research, 24(6), 434-441.

Mezey, M., \& Chiamulera, D. N. (1980). Implementation of a campus nursing and health information center in the baccalaureate curriculum. Journal of Nursing Education, 19(5), 7-10.

Nickles, T. (1985). Community nursing centers legislation. Legislative Update, I(1). Washington, DC: American Nurses' Association.

Ossler, C. C., Goodwin, M. S., Mariani, M., \& Gilliss, C. (1982). Establishment of a nursing clinic for faculty and student clinical practice. Nursing Outlook, 30(7), 402-405.

Ozimek, D., \& Yura, H. (1975). Who is the nurse practitioner? (Publication 151555). New York: National League for Nursing.

Riesch, S. (1982. June). Nurse managed center survey. Paper presented at the First Biennial Conference on Nurse-Managed Centers, Milwaukee.

Riesch, S., Felder, E., \& Stauder, C. (1980). Nursing centers can promote health for individuals, families, and communities. Nursing Administration Quarterly, 4, 1-8.

Snyder Hill, B. A. (1984). A Delphi applied to health care, practice, education, and educational administration curriculums. Image, 6, 16-18.

Sullivan, J. A. (1982). Research on nurse practitioners: Process behind the outcome? American Journal of Public Health, 72, 8-9.

Wyden, R. (1984). Community nursing center: An idea whose time has come. The Political Nurse, 4(1), 2. 


\section{Appendix}

\section{Table 1: Ranked Characteristics of Nurse-Managed Centers}

\begin{tabular}{|c|c|c|c|c|}
\hline Item & Rank & Number & $M$ & $S D$ \\
\hline $\begin{array}{l}\text { Direct access to a professional nurse should be an essential } \\
\text { aspect of NMCs. }\end{array}$ & 1 & 5 & 6.962 & .227 \\
\hline NMCs should have a strong referral network. & 2.5 & 27 & 6.960 & .198 \\
\hline $\begin{array}{l}\text { NMCs should promote client participation in their health } \\
\text { care. }\end{array}$ & 2.5 & 26 & 6.960 & .235 \\
\hline $\begin{array}{l}\text { Patients/clients should be treated holistically (mind, body, } \\
\text { and spirit) in NMCs. }\end{array}$ & 4 & 15 & 6.932 & .281 \\
\hline $\begin{array}{l}\text { A major purpose of NMCs should be to provide health } \\
\text { services for clients/patients. }\end{array}$ & 5.5 & 15 & 6.624 & .341 \\
\hline $\begin{array}{l}\text { Professional nurses should receive direct third-party } \\
\text { reimbursement for services provided in NMCs. }\end{array}$ & 5.5 & 17 & 6.924 & .383 \\
\hline $\begin{array}{l}\text { Professional nurses in NMCs should diagnose human } \\
\text { responses to actual and potential health problems. }\end{array}$ & 7 & 7 & 6.902 & .323 \\
\hline Health promotion should be a focus of NMCs. & 8 & 4 & 6.879 & .446 \\
\hline $\begin{array}{l}\text { Professional nurses in NMCs should treat human responses } \\
\text { to actual and potential health problems. }\end{array}$ & 9 & 8 & 6.872 & .375 \\
\hline $\begin{array}{l}\text { Patient/client health education should be a major function in } \\
\text { NMCs. }\end{array}$ & 10 & 11 & 6.857 & .566 \\
\hline NMCs should have consumer input. & 11 & 24 & 6.847 & .443 \\
\hline NMCs should be settings for nursing research. & 12 & 16 & 6.835 & 605 \\
\hline Self-responsibility for health should be promoted in NMCs. & 13 & 6 & 6.805 & .570 \\
\hline $\begin{array}{l}\text { The chief administrator of a NMC should be a professional } \\
\text { nurse. }\end{array}$ & 14 & 21 & 6.615 & .968 \\
\hline $\begin{array}{l}\text { NMCs should address the health problems of underserved } \\
\text { populations (e.g., poor, women, elderly, minorities). }\end{array}$ & 15 & 28 & 6.530 & .761 \\
\hline Disease prevention should be a focus of NMCs. & 16.5 & 3 & 6.489 & 1.098 \\
\hline NMCs should be based on nursing models of health. & 16.5 & 1 & 6.489 & 1.012 \\
\hline NMCs should be sites for student practice and learning. & 18 & 13 & 6.459 & .933 \\
\hline NMCs should be sites for faculty practice. & 19 & 12 & 6.271 & 1.142 \\
\hline $\begin{array}{l}\text { NMCs should include involvement of other health care } \\
\text { professionals (e.g., physicians, dieticians, physical } \\
\text { therapists). }\end{array}$ & 20 & 23 & 6.177 & .920 \\
\hline $\begin{array}{l}\text { Outcomes (in part) in NMCs should be primarily evaluated } \\
\text { on the results of treating nursing diagnoses. }\end{array}$ & 21 & 18 & 6.090 & 1.395 \\
\hline $\begin{array}{l}\text { Master's preparation in clinical nursing should be minimal- } \\
\text { level preparation for independent practice in a NMC. }\end{array}$ & 22 & 20 & 5.293 & 1.787 \\
\hline NMCs should have both a medical and nursing focus. & 23 & 25 & 4.218 & 1.601 \\
\hline $\begin{array}{l}\text { Bachelor's-prepared nurses should be allowed to practice } \\
\text { independently in a NMC. }\end{array}$ & 24 & 19 & 4.113 & 1.550 \\
\hline Professional nurses in NMCs should treat medical problems. & 25 & 10 & 3.947 & 1.975 \\
\hline Professionals in NMCs should diagnose medical problems. & 26 & 9 & 3.639 & 1.904 \\
\hline NMCs should be based on a biomedical disease model. & 27 & 2 & 2.235 & 1.711 \\
\hline NMCs should be administered by someone other than a & 28 & 22 & 1.893 & 1.416 \\
\hline
\end{tabular}


Fehring, Schulte, Riesch 11 